\title{
Project Proposal for Mellon Supra-Institutional Project on the Decolonial Turn (Unsettling Paradigms) - 2018.
}

\section{Project leaders: Zannie Bock}

Department of Linguistics, University of the Western Cape

\author{
Christopher Stroud \\ Centre for Multilingualism and Diversities Research \\ (CMDR), University of the Western Cape

\section{Title: Languages and Literacies in Higher Education: Reclaiming voices from the south.}

\section{BRIEF OUTLINE OF PROJECT}

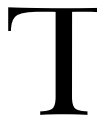
Twenty-first century migrations of people have triggered global diversity, and challenged established views and beliefs about language and belonging. While these challenges have in recent years become undeniably visible in the global north, they have been the experience of many living in the global south for decades. An important site of tension and change in particular is the higher education sector. Calls to encompass diversity through broadened epistemic access, decolonised curricula and transformed content have gained significant momentum in recent years.

In 2017, Mellon Supra-institutional funding supported a series of seminars and a workshop in which case studies on multilingualism from four different higher education contexts in South Africa were presented. The seminars went beyond profiling approaches which address these issues through the recognition and affirmation of different languages and groups. Instead, participants worked with the notion of linguistic citizenship, a decolonial lens, to highlight how innovative educational 
practices and policies - which centre multilingualism and diversity - can be used as tools for transformation, not only in the sense of enhancing epistemic access, but also in the broader sense of giving voice to more marginal participants. The papers are currently being edited into a volume that explores how the centring of multilingualism and diversity - not only as core pedagogic principles, but also as a methodology for transformation - can be used to enhance access and rekindle voice in the building of a more integrated and just society.

Following on this series of successful seminars, the current proposal aims to consolidate and further develop the emerging theoretical, methodological and didactic principles for language and literacy policy and practice in multilingual higher education contexts. More specifically, the pilot project will

- build on the studies and seminar contents to develop principles for the creative use of multilingual language practices in creating new forms of engagement across conventional categories of difference (e.g. white, black, coloured, isiXhosa, English, Afrikaans)

- develop the notion of 'linguistic citizenship' as a decolonial concept;

- create a resource group of colleagues from different institutions (e.g. UWC, Stellenbosch University, University of Sao Paulo (Professor Lynn Mario de Souza); Stockholm University.)

- consolidate a faculty-wide cooperation with the Creative Writing section of UWC's English Department and other language departments at the participating universities;

- develop and run a post-graduate module, Re-imagining Multilingualisms, in collaboration with Stellenbosch University.
- develop and trial a design for a transformative curriculum at scale, that is, in the Literacy module (LIN 323 ) for a $3^{\text {rd }}$ year cohort of 250 students at UWC.

An important outcome of the seminar deliberations in 2017 was the realisation of the necessity to shift our perspective on the way language and its role is conceptualised in higher education. This implies a rethinking of the bounded model of languages that sees multilingualism as multiple monolingualisms (isiXhosa, Afrikaans/Kaaps, English). Such a view encourages a focus on single languages rather than repertoires of 'entangled' multilingual resources. Furthermore, such a view disengages what are strictly construed as language practices from other semiotic/multimodal resources available to the student. In particular, it separates conceptualisations of language (genre, register, repertoire) from the affect, creativity and subjectivities that contribute to students' ownership of their intellectual projects.

The proposed project will be built around activities that require/ encourage post graduate students (on the new proposed module, Re-imagining Multilingualisms) and $3^{\text {rd }}$ year students (on an existing literacy module in the Linguistics Department) to explore their own multimodal, multilingual affiliations and subjectivities through various innovative practices of multimodal literacy. Further, an important feature of the project will be the joint lecturer-student development of theoretical concepts and facets of linguistic citizenship as they emerge in student discussions and portfolios. The portfolios of tutorial and assessment tasks will capture the ways in which students reflect on and engage with 
their multimodal and multilingual practices and understandings, and will attend specifically to how the complexity of practices may work as resources to enhance and deepen academic learning.

\section{Relation to the overall Mellon project on decolonising the curriculum}

A fundamental insight of decolonial theory is that the knowledge systems developed as part of colonialitymodernity that naturalise colonial subjugation (e.g. law, science, religion) need to be put into dialogue with, and reshaped and/or dislodged by, other, indigenous and local forms of knowledge. Decolonial theorists seek "a relocation and re-embodiment of knowledge" and a "plurality and intercultural dialogue in the building of new futures" (Veronelli, 2016: 404). Dussel's notion of transmodernity refers to the dialogical engagement of Western knowledges, colonialities, with local knowledges. The Portuguese sociologist, Boaventura de Sousa Santos, likewise speaks of the pluriversality of epistemologies. Mignolo refers to 'intra-dialogue', referring to the situation where individuals and groups (from different historical circumstances and backgrounds) with different experiences of coloniality engage with, share and develop new understandings/ knowledge frameworks. An important sense of unsettling paradigms would then be to explore how historically and differentially positioned marginalised groups create the conditions for mutual, critical, engagements around colonialitymodernity. A precondition for this is that dialogue and common-ground can be constructed. However, what it means to create a such a 'critical dialogue' in academic curricula - both theoretically and practically - and the constraints on doing so, is an increasingly urgent task in South African higher education.

One important dimension of this project is precisely to problematise the issue of mutuality and engagement in epistemological dialogue. In particular, the project addresses alternatives to conventional notions of language that do not 'gel' well with the thinking of decolonial theorists on the communicative conditions for alternative and decolonial epistemologies. Policies of mutuality through multilingualism have generally been conceptualised within a Linguistic Human Rights framework where recognition and affirmation of 'languages' is a key principle. However, by acknowledging and supporting the positionalities and identities that people have historically entertained in relation to language, the contemporary implications of the historical complexities involved in the colonial genesis of these languages has been glossed over. The very identities, social roles and languages recognised as 'historically marginalised' (and in need of affirmation as building blocks for new subaltern spaces of engagement) are those constructed and consolidated in the long, historical process of colonialitymodernity. This was - and remains in contemporary time - a process of invisibilisation and erasure of local voice and agency, and a recognition of speakers and their languages on the terms of the institutions of colonialitymodernity (cf. also Lugones (2011) on the implications of different histories of marginalisation for the problem of 'common ground', and Veronelli (2016) for the problematisation of the assumption of 'semiotic transparency' across these different histories). Glissant has noted how "too many Others and too many elsewhere disturb the flattened 
surface in order for systematic fixations to catch on in the really liveable world" (Glissant, 1997: 33). Mbembe (2017) echoing Fanon has argued for the need to find other forms of sociality through which to engage others outside of the conventional collectivities based in race, ethnicity etc. The core notion around which the project will centre is linguistic citizenship (LC). This notion engages precisely with the contradictions and tensions arising from the historical imposition of vulnerable identities and subjectivities and the creation of multilingual spaces as sites of contention and competition. It explores how linguistic and other semiotic forms assist in the emergence of a more autonomous sense of self, and how multilingualism can be reconceptualised as a space where an ethics of engagement across difference can be exercised.

Linguistic citizenship "aims to make visible the sociolinguistic complexity of language issues" (Stroud and Heugh, 2004: 192); to promote language as a political and economic 'site of struggle'; and to promote "respect for diversity and difference" and the "deconstruction of essentialist understandings of language and identity" (Stroud, 2001: 353). It refers to those occasions when people use language to exercise agency in circumstances that may be orthogonal, alongside or embedded in, or outside of, institutionalised democratic frameworks. Often, these are self-authored linguistic or multimodal practices which sculpt alternative, political, ethical, religious and epistemological subjectivities, to those which are otherwise given. Thus, one way of looking at LC is in conjunction with a notion of vulnerability, where it is understood as the emergent and sensitive process of disinhabiting imposed subjectivities, in ways which are cognisant of our relationality to others.
We anticipate that by building on, and further developing, the studies and series of seminars that have been carried out in 2017, we will be able to contribute to what Mbembe, following Fanon, has spoken of as the desirability of building 'new socialities' and attending to a politics of affinity (Phelan, 1996). The re-thinking of language and literacies along the lines of LC is critical to this.

\section{Expected theoretical and social gains of the project}

The project will contribute to the question of how "the notion of linguistic citizenship, one articulated at quite a high level of theoretical abstraction and with considerable intellectual sophistication, is to be made available and accessible to the individuals and communities it aims to empower" (Orman, 2012: 318). It will bring together groupings and socialities that are often seen as separate and different.

\section{Pedagogical benefits}

Building on students' resources (semiotic, linguistic, multimodal) and encouraging and offering spaces where writing (and other forms of semiotic expression) can be used in creative and innovative ways will stimulate both epistemological access and social engagement. Structuring affect and creativity through complex multilingualism and multimodality offer students across different groups the opportunity to explore and even forge their own practices and affiliations. Using LC as a tool to structure these reflections and interventions will, we believe, assist institutions to think through ways in which they can offer young people new spaces to learn and engage across difference. The context of an existing literacy module for developing these 
ideas and practices among a cohort of 250 students will provide valuable experiences of implementing decolonial and creative thinking at scale. In addition, it will also allow important synergies with other modules and departments within the Arts Faculty (UWC), and help to refigure the multilingual landscape of the institution.

\section{PROVISIONAL BUDGET 2018}

The project will engage participants both local and international universities, and will consolidate a reference group of academics working with multilingualism, education and decolonisation at Stellenbosch University, Stockholm University and the University of South Australia, as well as the Sao Paulo University in Brazil.
We therefore seek funding for: (a) start-up workshop for local participants and one international participant; (b) travel for the visiting scholar; (c) costs for materials and technical assistance; (d) compilation, editing and production of (i) a portfolio/volume of a selection of the project writing from participating students, with accompanying pedagogical/theoretical framing texts; (ii) the construction of a dedicated web platform, and (iii) a special issue of Multilingual Margins: A journal of linguistics from the periphery; (e) student assistantships to assist with data collection (tutorial/lecture observations, interviews with students, collection/ analysing of student projects, etc); and (f) consumables and running costs.

30 January 2018 


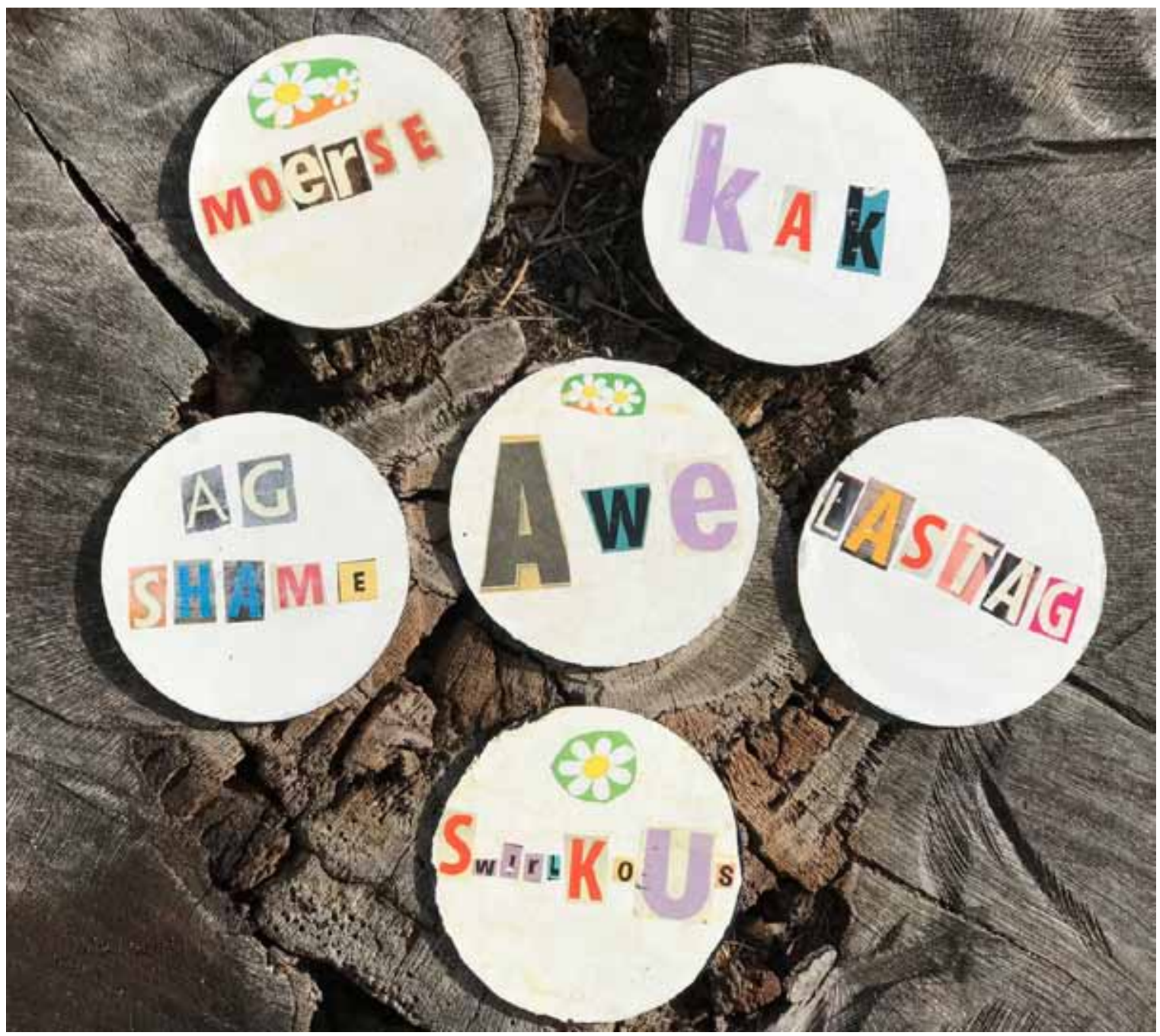

Fig 22. Coasters, by Lauren Abrahams. 